\title{
Numerical Calculation of Transient Flow of Polymer Foam in Porous Media
}

\author{
Wei Zhao, Haiqing Cui, Keliang Wang \\ Key Laboratory of Enhanced Oil and Gas Recovery of Ministry of Education, Northeast Petroleum University, \\ Daqing, China \\ Email: zhaoweinepu@163.com
}

Received 20 July 2015; accepted 11 August 2015; published 14 August 2015

Copyright (C) 2015 by authors and Scientific Research Publishing Inc.

This work is licensed under the Creative Commons Attribution International License (CC BY). http://creativecommons.org/licenses/by/4.0/

\section{(c) (i) Open Access}

\begin{abstract}
Based on the mathematical model of one dimension transient flow of the polymer foam in porous media, the numerical calculation method of the flow mentioned above by using the finite difference method is given. Through the experiments of one dimension transient flow of HPAM (Hydrolytic Polyacrylamide) foam in the artificial sandstone core, the HPAM foam generation and coalescence coefficient of the mathematical model mentioned above are determined. The profiles of the liquid phase saturation, the pressure drop and the number density of one dimension transient flow of HPAM foam with the dimensionless time in artificial sandstone core are numerically calculated and analyzed by using the numerical calculation method.
\end{abstract}

\section{Keywords}

Polymer Foam, Porous Media, Transient Flow, Mathematical Model, Numerical Calculation Method, Experimental Research

\section{Introduction}

The researches about the flow of aqueous foam in porous media are published more in literatures and reports. Kovseck [1] established the mathematical model of the transient flow of the aqueous foam in porous media based on the population balance equation and gave the relevant numerical calculation method; Bertin [2] [3] presented the mathematical model of transient flow of the aqueous foam in porous media based on the bubble correlation equation and compared the numerical calculated results of transient flow of the aqueous foam based on the bubble correlation equation in porous media with those based on the population balance equation. And the relevant research about the transient flow of polymer foam in porous media is limited in the experiment research in most cases now, due to its non-Newtonian property of liquid phase causing the flow of polymer foam more complicated than that of the aqueous foam in porous media. Sydansk [4] derived po- 
lymer-enhanced foams through the laboratory experiments, which were shown to exhibit, as compared with their counterpart conventional foams, the substantially higher effective viscosities and the much improved stability; Safouane, et al. [5] studied the drainage of foams made from Newtonian and non-Newtonian solutions of different viscosities and showed that foams made of solutions containing long flexible Poly Ethylene Oxide molecules counter-intuitively drained faster than foams made of Newtonian solutions of the same viscosity.

By using the finite difference method, one dimension transient flow of the polymer foam in porous media will be numerically calculated. In this paper, the profiles of the liquid phase saturation, the pressure drop and the number density of one dimension transient flow of HPAM foam with the dimensionless time in artificial sandstone core will be analyzed.

\section{Mathematical Model}

\subsection{Hypothesis Conditions}

1) The porous media is incompressible;

2) Polymer foam liquid phase is considered as the incompressible power-law fluid. The concentration of surfactant is constant. Gas phase obeys the ideal gas law;

3) Extensive Darcy law is adaptable, foam only influence on the gas phase relative permeability and viscocity;

4) Bubbles of the flow of the polymer foam in porous media are in the same size;

5) The effects of convection, diffusion, adsorption and gravitation of the polymer foam liquid phase in porous media are neglected;

6) The foam relative permeability is characterized by the gas relative permeability model.

\subsection{Mass Balance Equation}

The liquid and gas phase mass balance equations of one dimension transient flow of the polymer foam in porous media are [1] [6] [7]

$$
\begin{aligned}
& \frac{\partial\left(\phi \rho_{\mathrm{p}} S_{\mathrm{p}}\right)}{\partial t}=\frac{\partial}{\partial x}\left(\rho_{\mathrm{p}} \frac{K K_{\mathrm{rp}}}{\mu_{\mathrm{p}}}\left(\frac{\partial P_{\mathrm{p}}}{\partial x}\right)\right)+q_{\mathrm{p}} \\
& \frac{\partial\left(\phi \rho_{\mathrm{g}} S_{\mathrm{g}}\right)}{\partial t}=\frac{\partial}{\partial x}\left(\rho_{\mathrm{g}} \frac{K K_{\mathrm{rg}}}{\mu_{\mathrm{g}}}\left(\frac{\partial P_{\mathrm{g}}}{\partial x}\right)\right)+q_{\mathrm{g}}
\end{aligned}
$$

where

$$
\begin{gathered}
K_{\mathrm{rp}}=k_{\mathrm{rp}}^{\mathrm{o}}\left(\frac{S_{\mathrm{p}}-S_{\mathrm{pr}}}{1-S_{\mathrm{pr}}}\right)^{f} \\
K_{\mathrm{rg}}=k_{\mathrm{rg}}^{\mathrm{o}}\left(X_{\mathrm{f}}\left(1-\frac{S_{\mathrm{p}}-S_{\mathrm{pr}}}{1-S_{\mathrm{pr}}}\right)\right)^{g} \\
\rho_{\mathrm{g}}=\rho_{\mathrm{ga}} \frac{P_{\mathrm{g}}}{P_{\mathrm{ga}}} \\
\mu_{\mathrm{p}}=\left(K_{\mathrm{c}}\left[\frac{3 n+1}{n+1} \frac{1}{\sqrt{8 c^{\prime} K \phi}}\left(-K K_{\mathrm{rp}}\left(\frac{\partial P_{\mathrm{p}}}{\partial x}\right)\right)\right]^{n-1}\right)^{\frac{1}{n}} \\
\mu_{\mathrm{g}}=\mu_{\mathrm{g} 0}+\frac{\alpha n_{\mathrm{f}}}{v_{\mathrm{f}}^{c}}=\mu_{\mathrm{f}}
\end{gathered}
$$


where $\phi$ is the porosity; $\rho_{\mathrm{p}}$ the liquid phase mass density, $\mathrm{kg} / \mathrm{m}^{3} ; S_{\mathrm{p}}$ the saturation of liquid phase; $K$ the permeability of porous media, $\mathrm{m}^{2} ; K_{\mathrm{rp}}$ the liquid phase relative permeability; $\mu_{\mathrm{p}}$ the apparent viscosity of liquid phase, $\mathrm{Pa} \cdot \mathrm{s} ; P_{\mathrm{p}}$ the pressure of liquid phase, $\mathrm{Pa} ; q_{\mathrm{p}}$ the source-sink term of liquid phase, $\mathrm{kg} / \mathrm{m}^{3}$; $\rho_{\mathrm{g}}$ the gas mass density, $\mathrm{kg} / \mathrm{m}^{3} ; S_{\mathrm{g}}$ the saturation of gas phase; $K_{\mathrm{rg}}$ the gas phase relative permeability; $\mu_{\mathrm{g}}$ the gas viscosity, $\mathrm{Pa} \cdot \mathrm{s} ; P_{\mathrm{g}}$ the pressure of gas phase, $\mathrm{Pa} ; q_{\mathrm{g}}$ the source-sink term of gas phase, $\mathrm{kg} / \mathrm{m}^{3} ; S_{\mathrm{f}}$ the gas phase saturation of flowing foam; $n_{\mathrm{f}}$ the number density of flowing foam, $\mathrm{m}^{-3} ; S_{\mathrm{t}}$ the gas phase saturation of trapped foam; $n_{\mathrm{t}}$ the number density of trapped foam, $\mathrm{m}^{-3} ; u_{\mathrm{f}}$ the velocity of the flowing foam in porous media, $\mathrm{m} / \mathrm{s} ; v_{\mathrm{f}}$ the local interstitial velocity of flowing foam, $\mathrm{m} / \mathrm{s} ; k_{\mathrm{rp}}^{o}$ the liquid relative permeability where $S_{\mathrm{p}}=S_{\mathrm{pr}} ; S_{\mathrm{pr}}$ the connate liquid phase saturation; $f$ the index; $k_{\mathrm{rg}}^{\mathrm{op}}$ the gas relative permeability where $S_{\mathrm{p}}=S_{\mathrm{pr}} ; X_{\mathrm{f}}$ the fraction of the gas phase flow rate; $g$ the index; $\rho_{\mathrm{ga}}$ the air density under standard atmosphere, $\mathrm{kg} / \mathrm{m}^{3} ; P_{\mathrm{ga}}$ the pressure under standard atmosphere, $\mathrm{Pa} ; n$ flow behavior index of liquid phase; $K_{c}$ the consistency coefficient of liquid phase, $\mathrm{Pa} \cdot \mathrm{s}^{n} ; c^{\prime}$ the pore tortuosity; $\mu_{\mathrm{g} 0}$ the initial gas phase viscosity, $\mathrm{Pa} \cdot \mathrm{s} ; \alpha$ the constant of proportionality dependent primarily on the surfactant system, $\mathrm{Pa} \cdot \mathrm{s}^{2 / 3} \cdot \mathrm{m}^{10 / 3} ; n_{\mathrm{f}}$ the number density of flowing foam, $\mathrm{m}^{-3} ; v_{\mathrm{f}}$ the local interstitial velocity of flowing foam, $\mathrm{m} / \mathrm{s} ; c$ the index; $\mu_{\mathrm{f}}$ the foam effective viscosity, $\mathrm{Pa} \cdot \mathrm{s}$.

\subsection{Population Balance Equation}

The population balance equation of one dimension transient flow of the polymer foam in porous media is [1]

$$
\begin{gathered}
\frac{\partial\left(\phi\left(S_{\mathrm{f}} n_{\mathrm{f}}+S_{\mathrm{t}} n_{\mathrm{t}}\right)\right)}{\partial t}=-\frac{\partial\left(u_{\mathrm{f}} n_{\mathrm{f}}\right)}{\partial x}+\phi S_{\mathrm{g}}\left(k_{1} v_{\mathrm{f}}^{1 / 3} v_{\mathrm{p}}-k_{-1}^{o} \frac{\left(1-S_{\mathrm{p}}\right)}{\left(S_{\mathrm{p}}-S_{\mathrm{pc}}\right)} v_{\mathrm{f}} n_{\mathrm{f}}\right)+H_{\mathrm{b}} \\
S_{\mathrm{f}}=X_{\mathrm{f}} S_{\mathrm{g}} \\
S_{\mathrm{t}}=X_{\mathrm{t}} S_{\mathrm{g}} \\
u_{\mathrm{f}}=-\frac{K K_{\mathrm{rf}}}{\mu_{\mathrm{f}}} \frac{\partial P_{\mathrm{g}}}{\partial x} \\
X_{\mathrm{f}}+X_{\mathrm{t}}=1 \\
X_{\mathrm{t}}=X_{\mathrm{t}, \max }\left(\frac{\beta n_{\mathrm{t}}}{1+\beta n_{\mathrm{t}}}\right)
\end{gathered}
$$

where $S_{\mathrm{f}}$ is the gas phase saturation of flowing foam; $S_{\mathrm{t}}$ the gas phase saturation of trapped foam; $n_{\mathrm{t}}$ the number density of trapped foam, $\mathrm{m}^{-3} ; u_{\mathrm{f}}$ the velocity of the flowing foam in porous media, $\mathrm{m} / \mathrm{s} ; k_{1}$ the foam generation coefficient, $\mathrm{m}^{1 / 3} \cdot \mathrm{s}^{-13 / 3} ; v_{\mathrm{p}}$ the local interstitial liquid velocity, $\mathrm{m} / \mathrm{s} ; k_{-1}^{o}$ the foam coalescence coefficient, $\mathrm{m}^{-1} ; S_{\mathrm{pc}}$ the liquid phase saturation relavant to the limiting capillary pressure; $H_{\mathrm{b}}$ the source-sink term for foam bubbles in units of number per unit volume per unit time, $\mathrm{m}^{-3} ; X_{\mathrm{t}}$ the fraction of the gas phase trapped rate; $K_{\mathrm{rf}}$ the relative permeability of the foam that is flowing; $X_{\mathrm{t}, \max }$ the maximum fraction of the gas phase that trapped, $\beta$ trapped parameter.

\subsection{Assistant Equation}

\subsubsection{Relationship between Pressure}

$$
\begin{gathered}
P_{\mathrm{c}}=P_{\mathrm{g}}-P_{\mathrm{p}} \\
P_{\mathrm{c}}=\sigma \sqrt{\frac{\phi}{K}} J\left(S_{\mathrm{p}}\right)
\end{gathered}
$$

where [3] $P_{\mathrm{c}}$ is the capillary pressure, Pa; $\sigma$ the equilibrium surface tension, $\mathrm{N} / \mathrm{m} ; J\left(S_{\mathrm{p}}\right)$ the Leverett $J$ fuction.

\subsubsection{Relationship between Saturation}

$$
S_{\mathrm{p}}+S_{\mathrm{g}}=1
$$


2.4.3. Relationship between the Number Density of Flowing Foam and the Number Density of Trapped Foam

$$
n_{\mathrm{t}}=\frac{K_{\mathrm{f}} A_{\mathrm{f}} n_{\mathrm{f}}}{1+K_{\mathrm{f}} n_{\mathrm{f}}}
$$

where $K_{\mathrm{f}}, A_{\mathrm{f}}$ are the bubble trapped parameters [1].

\subsection{Definite Condition}

\subsubsection{Initial Condition}

$$
\begin{gathered}
P_{\mathrm{p}}(x, 0)=P_{\mathrm{pi}} \\
P_{\mathrm{g}}(x, 0)=0 \\
S_{\mathrm{p}}(x, 0)=1 \\
S_{\mathrm{g}}(x, 0)=0 \\
n_{\mathrm{f}}(x, 0)=0 \\
n_{\mathrm{t}}(x, 0)=0
\end{gathered}
$$

where $P_{\mathrm{pi}}$ is the initial liquid phase pressure, Pa.

\subsubsection{Boundary Condition}

$$
\begin{gathered}
-\left.\frac{K \cdot K_{\mathrm{rp}}}{\mu_{\mathrm{p}}} \frac{\partial P_{\mathrm{p}}}{\partial x}\right|_{t=t, x=0}=u_{\mathrm{p} i} \\
-\left.\frac{K \cdot K_{\mathrm{rg}}}{\mu_{\mathrm{g}}} \frac{\partial P_{\mathrm{g}}}{\partial x}\right|_{t=t, x=0}=u_{\mathrm{g} i} \\
P_{\mathrm{p}}(L, t)=P_{0} \\
P_{\mathrm{g}}(L, t)=P_{0} \\
n_{\mathrm{f}}(0, t)=n_{\mathrm{f}}(L, t)=0 \\
n_{\mathrm{t}}(0, t)=n_{\mathrm{t}}(L, t)=0
\end{gathered}
$$

where $u_{\mathrm{pi}}$ is the injection velocity of liquid phase, $\mathrm{m} / \mathrm{s} ; u_{\mathrm{gi}}$ the injection velocity of gas phase, $\mathrm{m} / \mathrm{s} ; L$ the length of porous media, $\mathrm{m}, P_{0}$ the backpressure, Pa .

The mass balance Equations (1) and (2), the bubble population balance Equation (8), the assistant equations (14), (16), (17), the definite condition (18)-(29) mentioned above consist of the mathematical model of one dimension transient flow of the polymer foam in porous media.

It is generally considered that the polymer foam generation coefficient $k_{1}$ and the coalescence coefficient $k_{-1}^{o}$ of the transient flow of the polymer foam in porous media are influenced by the physical properties of the polymer foam liquid phase, the polymer foam gas phase and the porous media, which needed to be determined by experiments.

\section{Numerical Calculation Method}

The mathematical model mentioned above is numerically calculated by using the finite difference method.

The mass balance Equations (1) and (2) of the mathematical model mentioned above are solved by using IMPES (Implicit Pressure Explicit Saturation) method. And the bubble population balance Equation (8) is solved by using TVD (Total Variation Diminish) three order methods [6] [8] [9]. 


\section{Experiment Research}

Through the laboratory experiments, with measuring the time-average pressure drop $\overline{\Delta P^{*}}$ of one dimension transient flow of the HPAM foam in the artificial sandstone core, the generation coefficient $k_{1}^{*}$ and the coalescence coefficient $k_{-1}^{0^{*}}$ of the mathematical model mentioned above in the artificial sandstone core are determined.

\subsection{Experiment Meter}

The main experiment meters include: DV-II + Pro viscometer, produced by American Brookfield Company, the measurement error is $\pm 1 \%$; TX-500C Spining interfacial tension meter, produced by American Bowing Company, the measurement error is $0.001 \mathrm{~mm}$.

\subsection{Experiment Material}

HPAM: foam liquid phase is the aqueous solution of $0.045 \mathrm{wt} \%$ HPAM, $0.200 \mathrm{wt} \%$ FL-605 and $0.830 \mathrm{wt} \%$ $\mathrm{NaCl}$, gas phase is air. The core is the homemade artificial sandstone core of $0.045 \mathrm{~m} \times 0.045 \mathrm{~m} \times 0.30 \mathrm{~m}$.

\subsection{Experiment Programme}

The experiment programme shows in Figure 1.

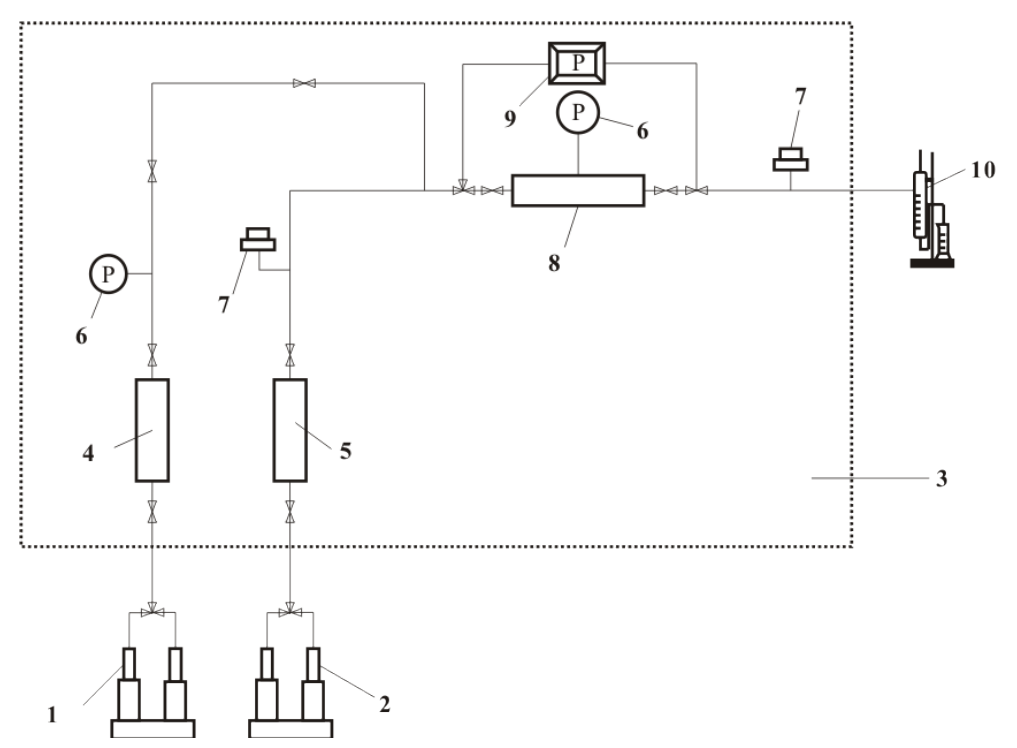

Figure 1. The experiment programme.

“1” D-250L liquid pump; “2” D-250L gas pump; “3” PMQ-2 foam performance measurement apparatus; “4” the liquid can; " 5 " the gas can; " 6 " digital manometer; "7" back-pressure valve; " 8 " the homemade artificial sandstone; "9" digital manometer; " 10 " cylinder.

Shut the back-pressure valve "7" of the outlet of the artificial sandstone core " 8 " of PMQ-2 foam performance measurement apparatus " 3 " and set the backpressure: Start D-250L liquid pump " 1 " and the liquid can " 4 " and set the liquid injection velocity $u_{\mathrm{p}}^{*}$; start D-250L gas pump "2" and the gas can " 5 " and set the air injection velocity $u_{\mathrm{g}}^{*}$; measure the time-average pressure drop $\overline{\Delta P^{*}}$ of the homemade artificial sandstone core " 8 " continuouslly by using the digital manometer " 9 " and "6" of " 3 ".

\subsection{Experimental Result}

\subsubsection{Experimental Parameters}

The experimental parameters of one dimension transient flow of the HPAM foam of $0.045 \mathrm{wt} \%$ HPAM, 0.200 wt\% FL-605 and $0.083 \mathrm{wt} \% \mathrm{NaCl}$ in the artificial sandstone core show as Table 1 [1]. 
Table 1. Experimental parameters.

\begin{tabular}{|c|c|c|c|}
\hline$\rho_{\mathrm{p}} / \mathrm{kg} \cdot \mathrm{m}^{-3}$ & 1000.24 & $\sigma \times 10^{-1} /(\mathrm{N} / \mathrm{m})$ & 0.28 \\
\hline$n$ & 0.7872 & $\rho_{\mathrm{ga}} \times 10^{-1} / \mathrm{kg} \cdot \mathrm{m}^{-3}$ & 11.03 \\
\hline$K_{c} \times 10^{-2} /\left(\mathrm{Pa} \cdot \mathrm{s}^{n}\right)$ & 0.5126 & $\mu_{\mathrm{g} 0} \times 10^{-4} / \mathrm{Pa} \cdot \mathrm{s}$ & 0.18 \\
\hline$L / \mathrm{m}$ & 0.30 & $\mu_{\mathrm{p} 0} \times 10^{-1} / \mathrm{Pa} \cdot \mathrm{s}$ & 0.01 \\
\hline$K / \mathrm{D}$ & 0.51 & $\beta \times 10^{-9} / \mathrm{m}^{3}$ & 1.00 \\
\hline$\phi$ & 0.25 & $X_{\mathrm{t}, \max }$ & 0.90 \\
\hline$c^{\prime}$ & 2.30 & $\alpha \times 10^{-14} / \mathrm{Pa} \cdot \mathrm{s}^{2 / 3} \cdot \mathrm{m}^{10 / 3}$ & 6.00 \\
\hline$k_{\mathrm{rp}}^{\circ}$ & 0.72 & c & 0.33 \\
\hline$k_{\mathrm{rg}}^{\circ}$ & 1.00 & $P_{0} / \mathrm{MPa}$ & 4.80 \\
\hline$f$ & 2.99 & $P_{\mathrm{pi}} / \mathrm{MPa}$ & 4.80 \\
\hline$g$ & 3.02 & $P_{\mathrm{ga}} / \mathrm{MPa}$ & 0.10 \\
\hline$S_{\mathrm{pr}}$ & 0.33 & $u_{\mathrm{p}}^{*} /(\mathrm{m} / \mathrm{d})$ & 0.046 \\
\hline$S_{\mathrm{pi}}$ & 1.00 & $u_{\mathrm{g}}^{*} /(\mathrm{m} / \mathrm{d})$ & 0.430 \\
\hline$S_{\mathrm{pc}}$ & 0.26 & $\overline{\Delta P^{*}} / \mathrm{kPa}$ & 1129.42 \\
\hline
\end{tabular}

\subsubsection{Determination of the Generation and Coalescence Coefficient}

By using the mathematical model, the relevant numerical calculated method, Table 1 mentioned above and B (Bisection) iterated algorithm, the generation coefficient $k_{1}^{*}$ and the coalescence coefficient $k_{-1}^{o^{*}}$ of one dimension transient flow of HPAM foam of $0.045 \mathrm{wt} \%$ HPAM, $0.200 \mathrm{wt} \%$ FL-605 surfactant and $0.830 \mathrm{wt} \%$ $\mathrm{NaCl}$ in the artificial sandstone core can be determined as $k_{1}^{*}=10.59 \times 10^{13} \mathrm{~m}^{1 / 3} \cdot \mathrm{s}^{-13 / 3}, k_{-1}^{0^{*}}=60.83 \mathrm{~m}^{-1}$ [1] [6].

\section{Numerical Calculation Results}

By using the mathematical model mentioned above, the relevant numerical calculated method, Table 1 and the generation coefficient $k_{1}^{*}$ and the coalescence coefficient $k_{-1}^{0^{*}}$, the profiles of the liquid phase saturation $S_{\mathrm{p}}$, the pressure drop $\Delta P_{\mathrm{p}}$, the number density $n_{\mathrm{f}}$ of one dimension transient flow of HPAM foam of $0.045 \mathrm{wt} \%$ HPAM, $0.200 \mathrm{wt} \%$ FL-605 surfactant and $0.830 \mathrm{wt} \% \mathrm{NaCl}$ in the artificial sandstone core with the dimensionless time PV are numerical calculated and analyzed.

\subsection{Profiles of Liquid Phase Saturation}

The profiles of the liquid phase saturation $S_{\mathrm{p}}$ of the one dimension transient flow of HPAM foam of $0.045 \mathrm{wt} \%$ HPAM, $0.200 \mathrm{wt} \%$ FL-605 surfactant and $0.830 \mathrm{wt} \% \mathrm{NaCl}$ in the artificial sandstone core with the dimensionless time PV show as Figure 2.

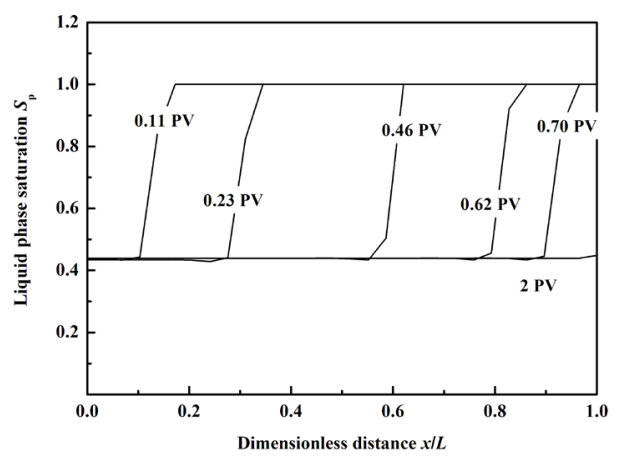

Figure 2. Profiles of liquid phase saturation $S_{\mathrm{p}}$ of HPAM foam with the dimensionless time PV. 
In Figure 2, the liquid phase saturation $S_{\mathrm{p}}$ of HPAM foam of $0.045 \mathrm{wt} \%$ HPAM, $0.200 \mathrm{wt} \%$ FL-605 surfactant and $0.830 \mathrm{wt} \% \mathrm{NaCl}$ at the flow front appears to be steep and sharp, the liquid phase saturation $S_{\mathrm{p}}$ of the upstream of the flow front is about 0.42 , and 1.00 of the downstream. The gas phase breaks through at about dimensionless time $0.70 \mathrm{PV}$. The liquid phase saturation $S_{\mathrm{p}}$ at steady state is about 0.42 . HPAM foam flows in a piston-like fashion in the artificial sandstone core. After HPAM foam flow front passing a particular location of the core, the liquid phase saturation $S_{\mathrm{p}}$ changes very little.

\subsection{Profiles of Pressure Drop}

The profiles of the pressure drop $\Delta P_{\mathrm{p}}$ of the one dimension transient flow of HPAM foam of 0.045 wt $\%$ HPAM, $0.200 \mathrm{wt} \%$ FL-605 surfactant and $0.830 \mathrm{wt} \% \mathrm{NaCl}$ in the artificial sandstone core with the dimensionless time PV show as Figure 3.

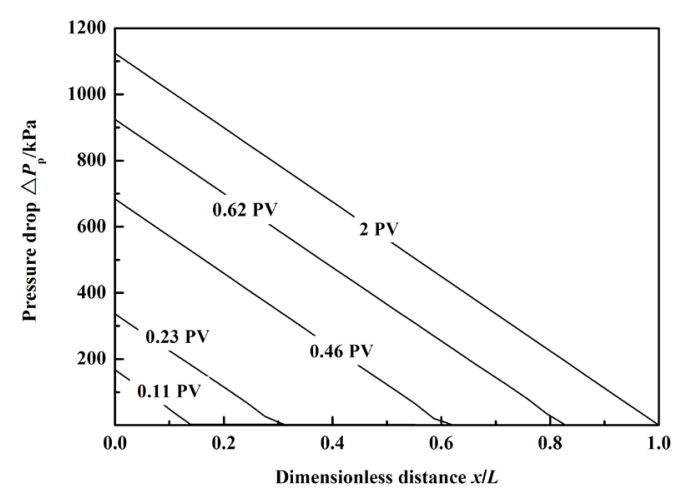

Figure 3. Profiles of pressure drop $\Delta P_{\mathrm{p}}$ of HPAM

foam with the dimensionless time PV.

In Figure 3, the pressure drop $\Delta P_{\mathrm{p}}$ of the flow of HPAM foam of $0.045 \mathrm{wt} \%$ HPAM, $0.200 \mathrm{wt} \%$ FL-605 surfactant and $0.830 \mathrm{wt} \% \mathrm{NaCl}$ decreases away from the core entrance with the dimensionless distance $\mathrm{x} / \mathrm{L}$. The pressure drop $\Delta P_{\mathrm{p}}$ of the downstream of the flow front is close to $0.00 \mathrm{kPa}$. The pressure drop $\Delta P_{\mathrm{p}}$ doesn't increase up to $1130.21 \mathrm{kPa}$ along with dimensionless time PV elapsing until about $2 \mathrm{PV}$. The steady pressure drop $\Delta P_{\mathrm{p}}$ is $1130.21 \mathrm{kPa}$.

\subsection{Profiles of Number Density of Flowing HPAM Foam}

The profiles of the number density $n_{\mathrm{f}}$ of the one dimension transient flow of HPAM foam of $0.045 \mathrm{wt} \%$ HPAM, $0.200 \mathrm{wt} \%$ FL-605 surfactant and $0.830 \mathrm{wt} \% \mathrm{NaCl}$ in the artificial sandstone core with the dimensionless time PV show as Figure 4.

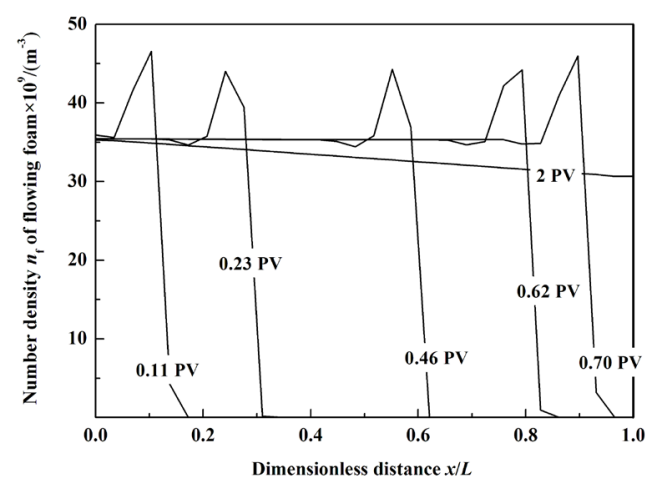

Figure 4. Profiles of the number density $n_{\mathrm{f}}$ of HPAM foam with the dimensionless time PV. 
In Figure 4, there is the flow front of the flow of HPAM foam of $0.045 \mathrm{wt} \%$ HPAM, $0.200 \mathrm{wt} \%$ FL-605 surfactant and $0.830 \mathrm{wt} \% \mathrm{NaCl}$ in the artificial sandstone core. The number density $n_{\mathrm{f}}$ of flowing HPAM foam reaches the peak value at the flow front. The steady state profile of the number density $n_{\mathrm{f}}$ of flowing HPAM foam appears at $2 \mathrm{PV}$, after which the number density $n_{\mathrm{f}}$ of flowing HPAM foam decreases from the inlet to the outlet.

\section{Experiment Verification}

By using the mathematical model, the relevant numerical calculated method, Table 1 and the generation coefficient $k_{1}^{*}$, the coalescence coefficient $k_{-1}^{0^{*}}$ mentioned above, the curves of the calculated pressure drop $\Delta P$ and the experiment pressure drop $\Delta P^{*}$ of one dimension transient flow of HPAM foam of $0.045 \mathrm{wt} \%$ HPAM, 0.200 wt\% FL-605 and $0.830 \mathrm{wt} \% \mathrm{NaCl}$ with dimensionless time PV in the artificial sandstone core are compared as Figure 5.

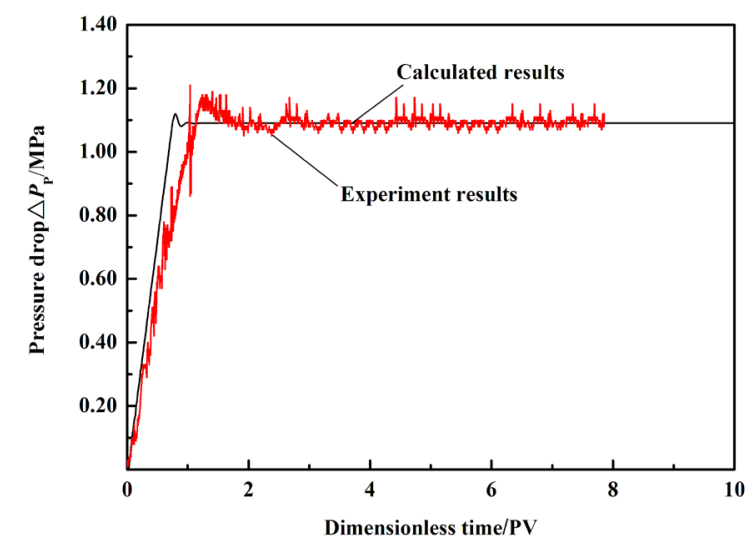

Figure 5. Comparison between the curves of the numerical calculated pressure drop $\Delta P$ and the experiment pressure drop $\Delta P^{*}$ of HPAM foam.

In Figure 5, the curves of the calculated pressure drop $\Delta P$ curve and the experiment pressure drop $\Delta P^{*}$ of one dimension transient flow of HPAM foam of $0.045 \mathrm{wt} \%$ HPAM, $0.200 \mathrm{wt} \% \mathrm{FL}-605$ and $0.830 \mathrm{wt} \% \mathrm{NaCl}$ in artificial sandstone core are basically coincided, which show that the mathematical model of one dimension transient flow of polymer foam in porous media and the relevant numerical calculation method in the paper are correct [10].

\section{Conclusions}

1) Based on the mathematical model of one dimension transient flow of the polymer foam in porous media, the numerical calculation method of the flow mentioned above by using the finite difference method is given;

2) Through the experiments, the generation coefficient and the coalescence coefficient of the transient flow of HPAM foam of $0.045 \mathrm{wt} \%$ HPAM, $0.200 \mathrm{wt} \%$ FL-605 surfactant and $0.830 \mathrm{wt} \% \mathrm{NaCl}$ in the artificial sandstone core are determined;

3) The profiles of the liquid phase saturation ,the pressure drop and the number density of one dimension transient flow of HPAM foam of $0.045 \mathrm{wt} \%$ HPAM, $0.200 \mathrm{wt} \%$ FL-605 and $0.830 \mathrm{wt} \% \mathrm{NaCl}$ with the dimensionless time in the artificial sandstone core are numerically calculated and analyzed.

4) Through the experiments, the mathematical model of one dimension transient flow of polymer foam in porous media and the relevant numerical calculation method are verified.

5) Based on the research results mentioned above, it needs the future study to continue working and researching for the polymer concentration influencing on the transient flow of the polymer foam in porous media.

\section{References}

[1] Kovseck, A.R. (1994) Foam Displacement in Porous Media: Experiment and Mechanistic Prediction by the Population 
Method. University of California at Berkely, Berkely.

[2] Bertin, H. (1997) Modeling Transient Foam Transport in Porous Media. Proceedings of the International Conference, Moscow, 1997, 187-206.

[3] Bertin, H.J., Quintard, M.Y. and Castainier, L.M. (1998) Development of a Bubble-Population Correlation for Foam-Flow Modeling in Porous Media. SPE Journal, 3, 356-362. http://dx.doi.org/10.2118/52596-pa

[4] Sydansk, R.D. (1994) Polymer-Enhanced Foams Part 1: Laboratory Development and Evaluation. SPE Advanced Technology Series, 2, 150-159. http://dx.doi.org/10.2118/25168-PA

[5] Safouane, M., Saint-Jalmes, A., Bergeron, V. and Langevin, D. (2006) Viscosity Effects in Foam Drainage: Newtonian and Non-Newtonian Foaming Fluids. The European Physical Journal E, 19, 195-202. http://dx.doi.org/10.1140/epje/e2006-00025-4

[6] Zhao, W. (2015) Flow of Polymer Foam in Porous Media. Northeast Petroleum University, Daqing.

[7] Garrouch, A.A. (1999) A Viscoelastic Model for Polymer Flow in Reservoir Rocks. Proceedings of the SPE Asia Pacific Oil and Gas Conference and Exhibition, Jakarta, 20-22 April 1999, 1-10. http://dx.doi.org/10.2118/54379-ms

[8] Aziz, K. and Settari, A. (1979) Petroleum Reservoir Simulation. Applied Science Publishers, London, 135-139.

[9] Leonard, B.P. (1984) Third Order Upwinding as a Rational Basis for Computational Fluid Dynamics. Proceedings of the Computational Techniques and Applications: CTAC-83, New York, 1983, 106-120.

[10] Kovscek, A.R. and Radke, C.J. (1993) Comprehensive Description of Transient Foam Flow in Porous Media. Proceedings of the NIPER/DOE Symposium on Field Application of Foams for Oil Production, Bakersfield, 11-12 February 1993, 1-14. 